\title{
Human Papilloma Virus: Prevalence, distribution and predictive value to lymphatic metastasis in penile carcinoma
}

Aluizio Gonçalves da Fonseca, Fernando Augusto Soares, Rommel Rodriguez Burbano, Rodrigo Vellasco Silvestre, Luis Otávio Amaral Duarte Pinto

Urology Department, Hospital Ophyr Loyola, Belem, PA, Brazil

\section{ABSTRACT}

Objectives: To evaluate the prevalence, distribution and association of HPV with histological pattern of worse prognosis of penile cancer, in order to evaluate its predictive value of inguinal metastasis, as well as evaluation of other previous reported prognostic factors. Material and Methods: Tumor samples of 82 patients with penile carcinoma were tested in order to establish the prevalence and distribution of genotypic HPV using PCR. HPV status was correlated to histopathological factors and the presence of inguinal mestastasis. The influence of several histological characteristics was also correlated to inguinal disease-free survival.

Results: Follow-up varied from 1 to 71 months (median 22 months). HPV DNA was identified in 60.9\% of sample, with higher prevalence of types 11 and 6 (64\% and 32\%, respectively). There was no significant correlation of the histological characteristics of worse prognosis of penile cancer with HPV status. Inguinal disease-free survival in 5 years did also not show HPV status influence $(\mathrm{p}=0.45)$. The only independent pathologic factors of inguinal metastasis were: stage $\mathrm{T} \geq \mathrm{T} 1 \mathrm{~b}-\mathrm{T} 4(\mathrm{p}=0.02)$, lymphovascular invasion $(\mathrm{p}=$ 0.04) and infiltrative invasion ( $\mathrm{p}=0.03)$.

Conclusions: HPV status and distribution had shown no correlation with worse prognosis of histological aspects, or predictive value for lymphatic metastasis in penile carcinoma.

\section{ARTICLE INFO}

\section{Key words:}

Penile Neoplasms; Humans;

Prevalence; Lymphatic

Metastasis; Biological Markers

Int Braz J Urol. 2013; 39: 542-50

Submitted for publication:

November 11, 2012

Accepted after revision:

May 25, 2013

\section{INTRODUCTION}

Epidermoid carcinoma of penis (ECP) is a rare neoplasm, but with high incidence in underdeveloped countries (1). In Brazil, the incidence varies from 2.9 to 6.8 cases/100.000 inhabitants/ year (2). In an epidemiological study in Pará State, the observed incidence was 5.7 cases/100.000 inhabitants/year (3).

Its etiology is associated with several risk factors, including presence of prepuce, bad hygienic habits, chronic dermatitis and smoking. Howe- ver, the most extensively studied factor is human papilloma virus infection (HPV) (4).

HPV has more than 100 subtypes that can be classified as with low (HPVlow) or high risk (HPVhigh) oncogenic potential (5). Its role in cervical uterine cancer is well established, but its association with ECP is still being discussed.

In patients with ECP, the presence of HPV varies from $15 \%$ to $80 \%$ suggesting that only a subgroup of these tumors is associated with HPV infection (6).

Natural history of the disease is characterized by progressive invasion of surrounding penile 
tissues, and posteriorly metastatic dissemination to inguinal lymph nodes (6). Lymph node involvement is the prognostic factor of worst impact on prognosis of disease-specific survival (6) and the analysis of this involvement is very important in order to determine the cure of the disease.

Nowadays, the available methods for staging regional lymph node involvement have low accuracy. For example, Gonzaga-Silva et al., using gamma probe in the sentinel lymph node, showed sensitivity of only $25 \%$ and $42.8 \%$ of false negative results (7).

The physical exam of inguinal region (inspection and palpation) is also inconclusive, since half the cases with lymph node involvement does not present tumor. Also, 20\% of patients without lymph node detected during physical exam present local micrometastasis (8).

Inguinal lymph node involvement is the most accurate method of staging to diagnose occult metastasis. However, it has significant morbidity and does not benefit a relevant subgroup of patients without metastasis (8).

In literature, several histological factors of the primary lesion were identified with predictive value of inguinal metastasis. These include: differentiation grade, tumor staging, and presence of neurovascular and lymph vascular invasion, with independent prognostic importance (9).

Although HPV infection is associated with the most aggressive histological subtypes, its value as a predictive factor of lymph node metastasis and prognosis is still debated (10).

The present study was conducted in a group of patients from Northern region of Brazil (Pará State), in order to evaluate the prevalence, distribution and association of HPV infection with histological pattern of worse prognosis in ECP and to determine its possible predictive value of lymph node metastasis.

\section{MATERIALS AND METHODS}

\section{Patients}

This study, as well as its consent inform, was approved by the Local Ethical Committee. Eighty-two patients with ECP were treated at the Hospital Ophir Loyola, Belém - Pará, from 2001 to 2008. The patients were submitted to penile amputation and the analysis of the lymph nodes followed a protocol proposed by the Urologic Department of the Hospital. All patients were prospectively evaluated, by follow-up appointments, medical files charts or telephonic contact of relatives.

\section{Treatment protocol}

Lymph node resection was performed after 4 to 6 weeks of the penile surgery. During this interval patients received antibioticotherapy with fluoroquinolones. For the patients with palpable inguinal lymph nodes after the antibiotic treatment it was performed bilateral superficial lymph node resection with freezing histological samples. Patients with T2-T4 staging and/or G2-G3 differentiation grade (according to TNM 2009 UICC System of Staging and Pathology) were also submitted to superficial bilateral lymph node resection.

In the presence of tumor involvement of superficial lymph nodes, radical lymphadenectomy was performed. Pelvic lymphadenectomy was performed in all cases with deep inguinal lymph node invasion.

The surgery was not performed in patients with Tis or T1, G1 staging, without lymph vascular invasion or palpable lymph nodes. These patients followed a careful ambulatory schedule of surveillance for at least five years.

\section{Pathological Analysis}

All samples were revised blindly by a single pathologist. The tumors were retrospectively staged according to 2009 TNM System.

Lymph vascular invasion (LVI) was defined as the presence of tumor cells in the interior of lymphatic veins, blood veins or arteries. Perineural invasion (PNI) was determined as the presence of tumor tissue next to peripheral nerve branches. As for invasion, the tumor was considered "infiltrative", when it was observed the presence of branches of malignant cells within the stroma, or "pushing", when it was observed an interface between the tumor and the host cells.

Histological subtypes were classified as usual, condylomatous, verrucous, basaloid, papillary, sarcomatoid and acantholysis. 


\section{HPV Analysis}

This part of the study was developed by the Papilloma Virus Laboratory of Instituto Evandro Chagas, a HPV referential laboratory of Brazilian Ministry of Health.

Parafin blocks were serially cut by microtome and the cuts were used for viral DNA detection.

Samples were submitted to polimerase chain reaction (PCR) using initially human beta globin G73 - 5'GAA GAG GGA AGG ACA GGT AC 3' e G74 - 5' CAA CTT CAT CCA CGT TCA CC 3' (PCR).

Viral gene specific reaction used the initiators GP5+ - 5' TTT GTT ACT GTG GTA GAT ACT AC 3' e GP6+ - 5' GAA AAA TAA ACT GTA AAT CAT ATT C 3', that were able to amplify a $150 \mathrm{pb}$ fragment of the L1 gene, that corresponds to a well preserved region of the virus genome.

After PCR, the identification of the virus was carried out using direct sequencing of the PCR product, using a capillary sequencer ABI 3130 Genetic analyser, Hitachi ${ }^{\odot}$.

The presence of HPV was classified in three subgroups:

high risk virus

HPVhigh - infection by one or more

HPVlow - infection by one or more low risk virus

HPVmult - presence of more than one subtype of virus in the sample, whether of high or low risk.

\section{Follow-up and statistical analysis}

Follow-up of patients was carried out through periodic ambulatory evaluations, quarterly in the first two years after surgery, and then semiannually.

The presence or absence of HPV infection, as well the presence of subgroups HPVhigh, HPVlow and HPVmult were related to several clinical and pathological variables, using the Chi-Square method or Fisher exact test.

The presence of inguinal metastasis was correlated to: pT, G, LVI, PNI, Infiltratative, Pushing, histological subtype and HPV status, using univariate and multivariate analysis by Cox proportional hazard method.

The analysis of inguinal disease-free interval (IDFI) in five years used the Kaplan-Meier method and the log Rank test. SPSS ${ }^{\circledR} 13.0$ was used for all analyses, and the result was considered significant if $\mathrm{p}<0.05$.

\section{RESULTS}

Median age of patients was 58 years (22-91 years) and follow-up ranged from 1 to 71 months (median 20 months).

\section{Presence of HPV DNA}

HPV DNA was detected in 60.9\% (50/82) fixed samples in paraffin. Viral distribution was: HPV11 (64\%), HPV6 (32\%), HPV16 (30\%), HPV53 (18\%), HPV33 (4\%) and subtypes 18, 68, 45, 51, 52 and $58(2 \%)$.

Subgroups HPVhigh, HPVlow and HPVmult were identified in 12/50 (24\%), 25/50 (50\%) and 25/50 (50\%) respectively. Viral types that predominated in each group were 16, 11 and 11.

Histological characteristics of subgroups HPV positive (HPVhigh, HPVlow and HPVmult) and HPV negative

Patients without HPV infection had predominantly infiltrative invasion. HPV positive group was correlated to more differentiated tumors (Table-1).

HPVhigh was associated more frequently to basaloid subtype, and rarely was present in patients with usual pattern. There was also a low prevalence of HVPhigh in patients with more advanced penile carcinoma (Table-1).

Most patients with usual pattern were infected by HPVlow. Condylomatous type was associated more frequently to HPVmult infection (Table-1).

Multiple logistic regression analysis did not show any histological variable independently related to status or HPV subgroup.

Inguinal metastasis-free survival in five years and risk factor, according to histological patterns

It was observed $56 \%$ of inguinal involvement of metastasis (46/82 patients). Inguinal metastasis-free survival (IMFS) probability in five years showed no difference between the positive and negative HPV groups (34\% x 29\%, p = 0.45) - Figure-1. 
Table 1 - Histopathological characteristics of 82 patients with penile cancer according to HPV positive $(n=50)$ or negative (n $=32)$, HPVhigh $(n=12)$, HPVlow $(n=25)$ and HPVmult $(n=25)$ groups.

\begin{tabular}{|c|c|c|c|c|c|c|c|c|c|}
\hline DNA-HPV & & & & & & & & & \\
\hline & $\mathrm{HPV}+$ & HPV- & $p$ & HPVHigh & $p$ & HPVlow & $p$ & HPVMult & $p$ \\
\hline TOTAL & $50(60.9)$ & $32(39)$ & & $12(50)$ & & $25(50)$ & & $25(50)$ & \\
\hline T1a & $14(28)$ & $8(72)$ & & $7(58)$ & & $5(22)$ & & $6(22)$ & \\
\hline T1b-T4 & $36(72)$ & $24(75)$ & $0.73^{1}$ & $5(42)$ & $0.01^{2}$ & $2(7)$ & $0.35^{1}$ & $1(7)$ & $0.70^{2}$ \\
\hline Grades 1 and 2 & $36(72$ & $15(46)$ & & $7(58)$ & & $18(72)$ & & $19(76)$ & \\
\hline Grade 3 & $14(28)$ & $17(53)$ & $0.02^{1}$ & $5(41)$ & $0.75^{1}$ & $7(28)$ & $0.22^{1}$ & $7(28)$ & $0.08^{1}$ \\
\hline LVI & $8(16)$ & $3(9)$ & $0.39^{1}$ & $3(11)$ & $0.20^{1}$ & $3(11)$ & $0.80^{1}$ & $3(11)$ & $0.80^{1}$ \\
\hline PNI & $11(22)$ & $7(21)$ & $0.98^{1}$ & $1(18)$ & $0.21^{1}$ & $6(18)$ & $0.76^{1}$ & $5(18)$ & $0.77^{1}$ \\
\hline \multicolumn{10}{|l|}{ INVASION } \\
\hline Infiltrative & $24(48)$ & $23(71)$ & $0.03^{2}$ & $4(47)$ & $0.06^{1}$ & $12(47)$ & $0.25^{1}$ & $13(47)$ & $0.51^{1}$ \\
\hline Pushing & $26(52)$ & $9(28)$ & & $8(35)$ & & $13(35)$ & & $12(35)$ & \\
\hline \multicolumn{10}{|l|}{ SUBTYPE } \\
\hline Usual & $37(74)$ & $23(71)$ & $0.83^{1}$ & $5(60)$ & $0.000^{2}$ & $23(60)$ & $0.01^{1}$ & $18(60)$ & $0.87^{1}$ \\
\hline Condilomatous & $3(6)$ & $1(3)$ & $0.55^{1}$ & $1(4)$ & $0.54^{2}$ & $0(4)$ & $0.17^{1}$ & $3(4)$ & $0.04^{2}$ \\
\hline Verrucous & $1(20)$ & $2(6)$ & $0.31^{1}$ & $1(3)$ & $0.35^{1}$ & $0(3)$ & $0.24^{1}$ & $0(3)$ & $0.24^{1}$ \\
\hline Basaloid & $4(8)$ & $0(0)$ & $0.10^{1}$ & $3(4)$ & $0.009^{2}$ & $1(4)$ & $0.80^{1}$ & $1(4)$ & $0.80^{1}$ \\
\hline Papillary & $2(4)$ & $3(9)$ & $0.32^{1}$ & $2(5)$ & $0.15^{1}$ & $0(5)$ & $0.12^{2}$ & $1(5)$ & $0.59^{1}$ \\
\hline Sarcomatoid & $2(4)$ & $3(9)$ & $0.32^{1}$ & $0(5)$ & $0.33^{1}$ & $0(5)$ & $0.12^{1}$ & $2(5)$ & $0.63^{1}$ \\
\hline Acantholysis & $1(2)$ & $0(0)$ & $0.42^{1}$ & $0(1)$ & $0.67^{1}$ & $1(1)$ & $0.12^{1}$ & $0(1)$ & $0.50^{1}$ \\
\hline $\mathrm{pN}$ & $29(58)$ & $17(53)$ & $0.66^{1}$ & $6(46)$ & $0.64^{1}$ & $15(46)$ & $0.63^{1}$ & $12(46)$ & $0.32^{1}$ \\
\hline
\end{tabular}

The values in parenthesis indicate percentage

1: Chi square test;

2: Fisher exact test. 
Figure 1 - Inguinal metastasis-free survival after treatment of the primary tumor showed no significant differences between hpv positive tumors (n50/82) or negative hpv tumors (n32/82), $\mathrm{p}=0.45$.

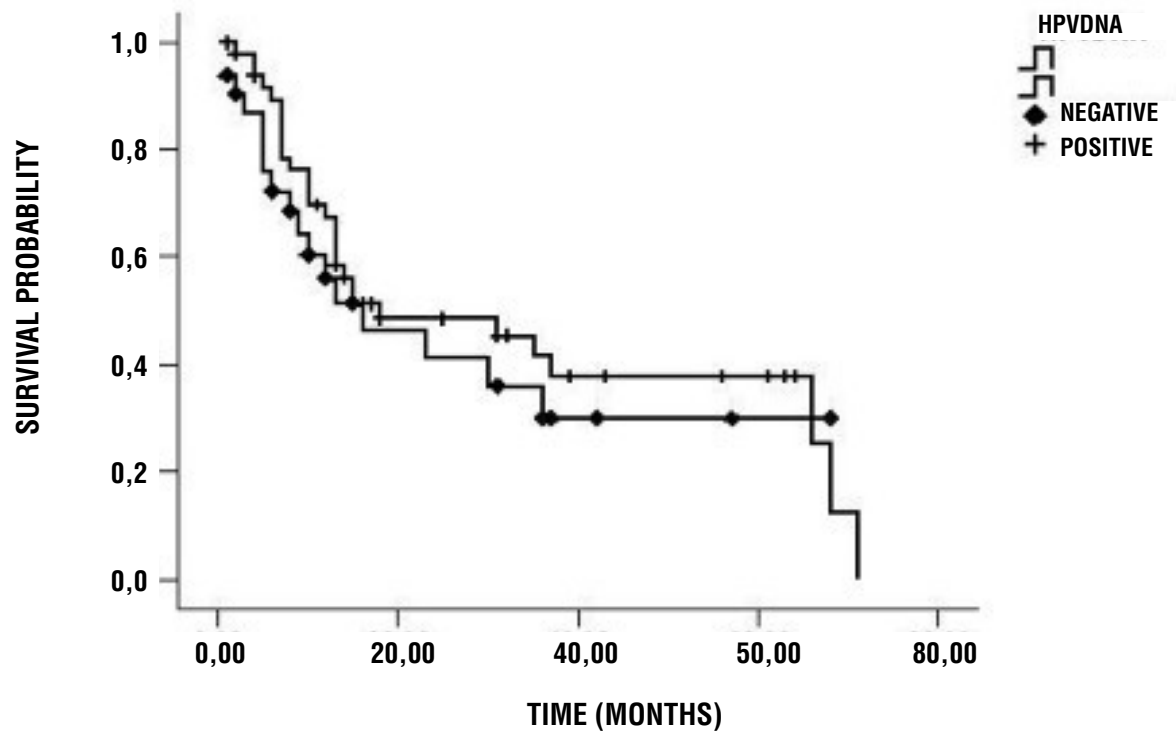

Likewise, there was no statistical significant difference of IMFS among the groups HPVhigh, HPVlow and HOVmult (Table-2).

Univariate analysis of IMFS in five years, according to histopatological patterns, showed that stage $\mathrm{T} \geq \mathrm{T} 1 \mathrm{~b}-\mathrm{T} 4(\mathrm{HR}=5.76)$, LVI $(\mathrm{HR}=2.90)$, PNI $(\mathrm{HR}=2.88)$, and infiltrative invasion $(\mathrm{HR}=2.68)$ were, decreasingly, strong predictors of inguinal metastasis, respectively 82.6\% (38/52), 100\% (11/11), 94.4\% (17/18) and 70.2\% (33/47) (Table-2).

Only sarcomatoid subtype was related to regional metastasis (4/5). Papillary subtype showed negative correlation to metastasis in 100\% (0/5).

Multivariated analysis showed that $\mathrm{T} \geq \mathrm{T} 1 \mathrm{~b}$ -T4, LVI and infiltrative invasion were strong independent predictors of inguinal metastasis (Table-3).

\section{DISCUSSION}

The present study is the first scientific report of the presence of HPV and its genotype variants correlated to ECP in a northern state of Brazil, a region with high prevalence of the disease.

In this sample, HPV prevalence in patients with ECP was $60.9 \%$, in accordance to literature. It is reported a variation of $14 \%$ to $100 \%$ (11). Miral-
les-Guri et al. metanalysis in 2009, comprasing 30 studies and 1266 patients with ECP reported a HPV DNA prevalence of 47.9\%. In South America, viral DNA was specifically found in $40.7 \%$ of tumors (12).

As for the genotype distribution, in our sample there was a clear prevalence of types 11 and 6, contrary to the previous report of Bezerra et al., that reported an absolute prevalence of type 16 (12). We also registered infection by multiple HPV genotypes in $30.4 \%$ (25/50), contrary to the study by Krustrup et al., that did not show multiple viral infections in their sample (13).

Variations of the reported prevalence of DNA HPV are mainly due to different techniques of sampling, studied population, detection methods, tumoral tissue storage and inclusion of multiple histological subtypes (14).

The role of HPV in epithelium carcinogenesis of uterine cervix is well established. In more than 95\% of patients it is observed several high risk subtypes of virus infection (15); however, in ECP, the viral infection is not mandatory and there are several other causes not related to HPV infection (15). Relation of genital tumors and HPVhigh is stimulating research and interest of the biological potential viral interference on metastasis and disease prognosis. 
Table 2 - Inguinal metastasis-free survival index in 5 years and risk rate according to clinical and pathological variables univariate analysis

\begin{tabular}{|c|c|c|c|c|}
\hline & $\begin{array}{c}\text { Number of } \\
\text { patients }\end{array}$ & $\begin{array}{l}\text { IMFS in } 5 \text { years } \\
(95 \% \text { IC) }(\%)\end{array}$ & $\begin{array}{c}\text { p Value } \\
\text { (Log-Rank test) }\end{array}$ & $\begin{array}{l}\text { Risk rate } \\
(\text { IC95\%) }\end{array}$ \\
\hline \multicolumn{5}{|l|}{ pT } \\
\hline T1a & 23 & $59(45-73)$ & 0.002 & $5.76(1.78-18.64)$ \\
\hline $\mathrm{T} 1 \mathrm{~b}-\mathrm{T} 4$ & 57 & $26(19-33)$ & & \\
\hline \multicolumn{5}{|l|}{ GRADES } \\
\hline $1-2$ & 51 & $34(25-43)$ & 0.42 & $1.27(0.70-2.31)$ \\
\hline 3 & 31 & $28(18-39)$ & & \\
\hline \multicolumn{5}{|l|}{ LVI } \\
\hline Present & 11 & $14(3-25)$ & 0.0004 & $2.90(1.44-5.81)$ \\
\hline Absent & 71 & $36(28-43)$ & & \\
\hline \multicolumn{5}{|l|}{ PNI } \\
\hline Present & 18 & $14(6-22)$ & 0.000 & $2.88(1.54-5.37)$ \\
\hline Absent & 64 & $39(30-47)$ & & \\
\hline \multicolumn{5}{|l|}{ INVASION } \\
\hline Infiltrative & 47 & $23(16-31)$ & 0.003 & $2.68(1.38-5.22)$ \\
\hline Pushing & 35 & $46(35-57)$ & & \\
\hline \multicolumn{5}{|l|}{ SUBTYPE } \\
\hline Usual & 60 & $33(25-41)$ & 0.55 & $0.81(0.39-1.65)$ \\
\hline Condilomatous & 4 & $38(10-66)$ & 0.52 & $0.53(0.73-3.88)$ \\
\hline Verrucous & 3 & $9(2-15)$ & 0.99 & $1.00(0.13-7.38)$ \\
\hline Basaloid & 4 & $12(9-15)$ & 0.24 & $1.96(0.60-6.45)$ \\
\hline Papillary & 5 & $9(4-13)$ & 0.02 & $0.04(0.00-15.59)$ \\
\hline Sarcomatoid & 5 & $9(4-13)$ & 0.02 & $3.02(1.05-8.64)$ \\
\hline Acantholysis & 1 & $7(7-7)$ & 0.14 & $3.88(0.51-29.2)$ \\
\hline \multicolumn{5}{|l|}{ HPV } \\
\hline Positive & 50 & $34(25-43)$ & 0.45 & $0.79(0.43-1.46)$ \\
\hline Negative & 32 & $29(18-40)$ & & \\
\hline
\end{tabular}


Table 3 - Inguinal metastasis-free survival index in 5 years and risk rate according to clinical and pathological variables multivariate analysis.

COX multivariate regression analysis - independent risk factors for inguinal metastasis

\begin{tabular}{lcc}
\hline Variables & Risk rate $(I C 95 \%)$ & "p" value \\
\hline pT1axpT1b-4 (pT1b-4) & $2.67(1.16-6.15)$ & 0.02 \\
$\mathrm{LVI}+$ & $2.09(1.03-4.22)$ & 0.03 \\
Infiltrative invasion & $2.00(1.00-4.03)$ & 0.04 \\
\hline
\end{tabular}

Several authors tried to relate viral infection and histological pattern of worse prognosis (16-18). Scheiner et al. (16), Lont et al. (17) and Kirrander et al. (18) did not find such evidence. However, Gregoire et al. (19) and Krustrup et al. (13) reported a significant statistical association between HPVhigh infection and high risk tumors. Our studied showed that the only positive association was between the prevalence of HPVhigh in 75\% of basaloid tumors, with worse prognosis. Cubilla et al. (20) reported the same association.

Guimaraes et al. evaluated 14 cases of basaloid tumors, and reported 50\% of inguinal metastasis. In our sample we observed 75\% (3/4 patients) (21). Despite the small number of patients with this histological subtype of tumor, we believe that this association should be more investigated hereafter.

The recommendations for lymphadenectomies without the presence of inguinal lymph node disease are based upon predictive factors related to the primary lesion, mainly tumor stage and cellular differentiation grade. However, overtreatment can reach $82 \%$ of cases (22). In our sample, this was observed in 88\% (30/34) even with the use of a strict protocol. It is necessary to search for non-invasive biomarkers with good accuracy, to predict the risk of metastatic lymph node involvement in patients with penile cancer $(22,23)$. In our series, there was no association between the presence or distribution of HPV genotype with lymph node disease, as reported by other authors $(13,19)$. At present, there are no evidences indicating the use of HPV detection in order to decide to perform lym- phadenectomies. Surprisingly, Lont et al., although failed to associate HPV status and lymph node metastasis, showed better specific-disease survival in patients with ECP associated with high risk virus $(p=0.03)$ (17). In order to avoid bias in our study, we only evaluated inguinal disease-free survival (IDFI), that did not show differences between HPV positive and negative groups $(\mathrm{p}=0.45)$.

Several pathological and molecular risk factor are being described in order to improve lymph node evaluation $(24,25)$. Among pathological predictive factors, only PNI, LVI and histological grade are independent factors to predict lymph node involvement (25). In our study, tumor stage $\geq \mathrm{T} 1 \mathrm{~b}-\mathrm{T} 4$, LVI, PNI, infiltrative invasion and sarcomatoid histological subtype are the histological factors related to lymph node metastasis in a univariate analysis.

There was no significant difference among the cellular differentiation grades as prognostic factors, in spite of the reduced sample. However, pathological heterogeneity, with more than a grade presented in the same tumor is rarely considered in different studies.

Multivariate regression analysis showed that only $\geq \mathrm{T} 1 \mathrm{~b}-\mathrm{T} 4$ tumors, LVI and infiltrative pattern were independent factors, and $\mathrm{T}$ stage was the most important $(\mathrm{HR}=2.67, \mathrm{p}=$ 0.02 ). The reported differences in several series are mainly caused by methodology, therapeutic approach and heterogeneity of the studied population. These limitations must be contoured in order to obtain a better validation of these risk factors for inguinal metastasis. 


\section{CONCLUSIONS}

Observed HPV prevalence was similar to previous studies. However, there was a predominance of the low risk viral group. There was no significant association between HPV status or HPV subgroups and histological worse prognostic factors. HPV detection had no use as predictive value of inguinal metastasis. Tumor staging, lymph-vascular invasion and infiltrative pattern were independent risk factors for lymph node involvement.

\section{CONFLICT OF INTEREST}

None declared.

\section{REFERENCES}

1. Backes DM, Kurman RJ, Pimenta JM, Smith JS: Systematic review of human papillomavirus prevalence in invasive penile cancer. Cancer Causes Control. 2009; 20: 449-57.

2. Favorito LA, Nardi AC, Ronalsa M, Zequi SC, Sampaio FJ, Glina S: Epidemiologic study on penile cancer in Brazil. Int Braz J Urol. 2008; 34: 587-91; discussion 591-3.

3. Fonseca AGda, Pinto JASA, Marques MC, Drosdroski FS, Fonseca Neto LORda: Estudo epidemiológico do câncer de pênis no Estado do Pará, Brasil. Rev Pan-Amaz Saude. 2010; 1: 85-90.

4. Bleeker MC, Heideman DA, Snijders PJ, Horenblas S, Dillner J, Meijer CJ: Penile cancer: epidemiology, pathogenesis and prevention. World J rol. 2009; 27: 141-50.

5. Tornesello ML, Duraturo ML, Losito S, Botti G, Pilotti S, Stefanon $B$, et al:: Human papillomavirus genotypes and HPV16 variants in penile carcinoma. Int J Cancer. 2008; 122: 132-7.

6. Pompeo ACL, Billis A: Carcinoma epidermóide do pênis. Int Braz J Urol. 2003; 29 (Suppl. 1): 44-50.

7. Gonzaga-Silva LF, Tavares JM, Freitas FC, Tomas Filho ME, Oliveira VP, Lima MV: The isolated gamma probe technique for sentinel node penile carcinoma detection is unreliable. Int Braz J Urol. 2007; 33: 58-63; discussion 64-7.

8. Pettaway CA, Horenblas S: Penile cancer: incremental insights into etiology, diagnosis, staging, and management. World J Urol. 2009; 27: 139-40.

9. BE Stephen, BR David, CC Carolyn, GF April, LG Frederick, T Andy, III: AJCC Cancer Staging Manual. Philadelphia, Lippincott. 2010; Seventh Edition, 2010; pp.447.

10. Cubilla AL: The role of pathologic prognostic factors in squamous cell carcinoma of the penis. World J Urol. 2009; 27: 169-77.
11. Miralles-Guri C, Bruni L, Cubilla AL, Castellsagué X, Bosch FX de Sanjosé S: Human papillomavirus prevalence and type distribution in penile carcinoma. J Clin Pathol. 2009; 62: 870-8.

12. Bezerra AL, Lopes A, Santiago GH, Ribeiro KC, Latorre MR Villa LL: Human papillomavirus as a prognostic factor in carcinoma of the penis: analysis of 82 patients treated with amputation andbilateral lymphadenectomy. Cancer. 2001; 91 : 2315-21.

13. Krustrup D, Jensen HL, van den Brule AJ, Frisch M: Histological characteristics of human papilloma-virus-positive and -negative invasive and in situ squamous cell tumours of the penis. Int J Exp Pathol. 2009; 90: 182-9.

14. Anic GM, Giuliano AR: Genital HPV infection and related lesions in men. Prev Med. 2011; 53: S36-41.

15. Rubin MA, Kleter B, Zhou M, Ayala G, Cubilla AL, Quint WG, et al.: Detection and typing of human papillomavirus DNA in penile carcinoma: evidence for multiple independent pathways ofpenile carcinogenesis. Am J Pathol. 2001; 159: 1211-8.

16. Scheiner MA, Campos MM, Ornellas AA, Chin EW, Ornellas $\mathrm{MH}$, Andrada-Serpa MJ: Human papillomavirus and penile cancers in Rio de Janeiro, Brazil: HPV typing and clinical features. Int Braz J Urol. 2008; 34: 467-74; discussion 475-6.

17. Lont AP, Kroon BK, Horenblas S, Gallee MP, Berkhof J, Meijer CJ, et al.: Presence of high-risk human papillomavirus DNA in penile carcinoma predicts favorable outcome in survival. Int $\mathrm{J}$ Cancer. 2006; 119: 1078-81.

18. Kirrander P, Kolaric A, Helenius G, Windahl T, Andrén 0 , Stark JR, et al.: Human papillomavirus prevalence, distribution and correlation to histopathological parameters in a large Swedish cohort ofmen with penile carcinoma. BJU Int. 2011; 108: 355-9.

19. Gregoire L, Cubilla AL, Reuter VE, Haas GP, Lancaster WD: Preferential association of human papillomavirus with highgrade histologic variants of penile-invasive squamous cellcarcinoma. J Natl Cancer Inst. 1995; 87: 1705-9.

20. Cubilla AL, Lloveras B, Alejo M, Clavero 0, Chaux A, Kasamatsu $E$, et al.: The basaloid cell is the best tissue marker for human papillomavirus in invasive penile squamous cell carcinoma: a study of202 cases from Paraguay. Am J Surg Pathol. 2010; 34: 104-14.

21. Guimaraes G, Werneck da Cunha I, Soares F, Lopez A, Torres JJ, Chaux A, et al.: WHO histological classiWcation, regional metástasis and outcome in 375 surgically treated patients with penile SCC. Mod Pathol. 2007; 20: 150A.

22. Ficarra V, Novara G, Boscolo-Berto R, Artibani W, Kattan MW: How accurate are present risk group assignment tools in penile cancer? World J Urol. 2009; 27: 155-60.

23. Kroon BK, Valdés Olmos RA, van Tinteren $H$, Nieweg $O E$, Horenblas S: Reproducibility of lymphoscintigraphy for lymphatic mapping in patients with penile carcinoma. J Urol. 2005; 174: 2214-7. 
24. Chaux A, Tamboli P, Ayala A, Soares F, Rodríguez I, Barreto J et al.: Warty-basaloid carcinoma: clinicopathological features of a distinctive penile neoplasm. Report of 45 cases. Mod Pathol. 2010; 23: 896-904.
25. Lopes A, Hidalgo GS, Kowalski LP, Torloni H, Rossi BM, Fonseca FP: Prognostic factors in carcinoma of the penis: multivariate analysis of 145 patients treated with amputation andIymphadenectomy. J Urol. 1996; 156: 1637-42.

Correspondence address:

Dr. Aluizio Gonçalves da Fonseca Av. Conselheiro Furtado 1625, Apto 401, Nazaré Belém, PA, 66040-100, Brazil FAX: + $55913223-3878$

E-mail: aluiziodafonseca@uol.com.br 